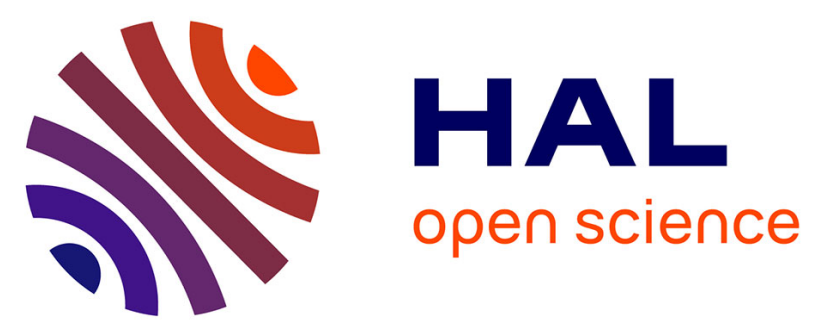

\title{
Symmetry loss of heptamethine cyanines: an example of dipole generation by ion-pairing effect
}

\author{
Simon Pascal, Pierre-Antoine Bouit, Boris Le Guennic, Stephane Parola, \\ Olivier Maury, Chantal Andraud
}

\section{- To cite this version:}

Simon Pascal, Pierre-Antoine Bouit, Boris Le Guennic, Stephane Parola, Olivier Maury, et al.. Symmetry loss of heptamethine cyanines: an example of dipole generation by ion-pairing effect. Proceedings of SPIE, the International Society for Optical Engineering, 2013, Organic Photonic Materials and Devices XV;, 8622, pp.86220F. 10.1117/12.2008220 . hal-01245529

\author{
HAL Id: hal-01245529 \\ https://hal.science/hal-01245529
}

Submitted on 23 Jul 2020

HAL is a multi-disciplinary open access archive for the deposit and dissemination of scientific research documents, whether they are published or not. The documents may come from teaching and research institutions in France or abroad, or from public or private research centers.
L'archive ouverte pluridisciplinaire HAL, est destinée au dépôt et à la diffusion de documents scientifiques de niveau recherche, publiés ou non, émanant des établissements d'enseignement et de recherche français ou étrangers, des laboratoires publics ou privés. 


\title{
Symmetry loss of heptamethine cyanines: an example of dipole generation by ion-pairing effect
}

\author{
Simon Pascal, ${ }^{\mathrm{a}}$ Pierre-Antoine Bouit, ${ }^{\mathrm{a}, \mathrm{b}}$ Boris Le Guennic, ${ }^{\mathrm{b}}$ Olivier Maury ${ }^{\mathrm{a} *}$ and Chantal Andraud ${ }^{\mathrm{a}^{*}}$ \\ ${ }^{a}$ Laboratoire de Chimie CNRS UMR 5182, Université Lyon 1, Ecole Normale Supérieure de Lyon, \\ 46 allée d'Italie, 69364 Lyon Cedex 07 \\ ${ }^{\mathrm{b}}$ Institut des Sciences Chimiques de Rennes, \\ UMR 6226 CNRS-Université de Rennes 1, 35042 Rennes Cedex, France. \\ *olivier.maury@ens-lyon.fr; chantal.andraud@ens-lyon.fr
}

\begin{abstract}
The development of near-infrared dyes for third order nonlinear optical applications and particularly for optical power limiting at telecommunications wavelengths triggered the revival of old dyes like polymethine dyes featuring an odd number of carbon atoms. Currently numerous research endeavor is focused on the understanding of their spectroscopy in solution and in the solid state in close relationship with their electronic structure. In this context, the dramatic effect of the counter ion on the heptamethine optical properties was highlighted depending on the dissociating character of the media. The unusual consideration of this parameter allows us to explore the so-called "cyanine limit" and to finely tune the heptamethine absorption in view of future use as dopant in a material for optical limiting applications.
\end{abstract}

Keywords: Cyanine, spectroscopy, ion-pairing, optical power limiting

\section{INTRODUCTION}

Polymethine dyes are old chromophores that exhibits intriguing spectroscopic properties i.e. cyanine type sharp transition localized in the near-infrared (NIR) region. Initially used for photography applications, they found a second life this last decade in the field of photonics with the development of near-infrared applications like bio-imaging, photovoltaics, nonlinear optics...(1-4) In the field of nonlinear optics, the development of frequency tunable pulsed laser sources in the NIR, and particularly at telecommunications wavelengths (1300-1500 nm), encourages the scientific community to design chromophres featuring optimized two-photon cross-section in this spectral range for signal processing applications (optical power stabilization, pulse suppression, optical power limiting) and of course polymethine dyes were extensively studied for such purposes in solution for two-photon cross-section determination, $(5,6)$ optical power limiting $(7,8)$ or in the solid state for all-optical signal processing. (9) The preparation of solid state functional material is of prime importance for the design of real device but the high concentration of dopant generally results in the broadening of the transition indicating a loss of the cyanine type absorption. This phenomenon is generally ascribed to aggregates formation or phase segregation known to occur at high concentration. In order to tackle this drawback, the increase of the steric hindrance of polymethine was successfully undertaken. $(10,11)$ Herein, we will emphasis the crucial role of the counter ion on the photophysical properties of polymethine dyes in solution and in the solid state.

\section{Results and discussion}

\subsection{Cyanines and dipolar polymethines}

The main structural characteristic of a polymethine dye is the presence a conjugated skeleton containing an odd number of $\mathrm{sp}^{2}$ carbon atoms bridging two electro-donating (D) or -withdrawing (A) extremities; the length of the chain characterizes the chromophore's sub-class, mono, penta, hepta and nonamethine being the most frequently encountered. The end-group can be either identical or different leading to symmetrical or unsymmetrical polymethine, respectively. From an electronic point of view, the electron density can be symmetrically distributed over the conjugated chain defining 
the so-called cyanine character featuring characteristic spectroscopic properties, namely a sharp absorption called solitonic with exceptional intensity and a typical shape shifted in the NIR and a very small Stockes shift. On the other hand an unsymmetrical electronic structure presents a typical charge transfer $(C T)$ or dipolar behavior with a broad structureless transition with a larger Stokes shift (Figure 1). As a general rule, symmetrical polymethines present a cyanine behavior and unsymmetrical polymethines present a CT behavior explaining the confusion between the structure and the electronic description. In some rare cases, it is possible for a given structure to cross the cyanine limit that is to switch form cyanine to CT behavior or vice-versa under external stimulus. As example in the cases of unsymmetrical structure it is possible to move from a CT to a cyanine behavior by increasing the solvent polarity. (12) In the case of symmetrical structures, the switching from of cyanine to a CT behavior is scarcer: one can mention the old Brooker's experiment (13) fully rationalized by Tolbert in 1997 (14) by "symmetry collapse" upon increasing the length of the conjugated chain. The cyanine character is conserved in the case of relatively short $\pi$-conjugated chains (up to 9-13 carbon atoms) but is progressively lost for longer chains.

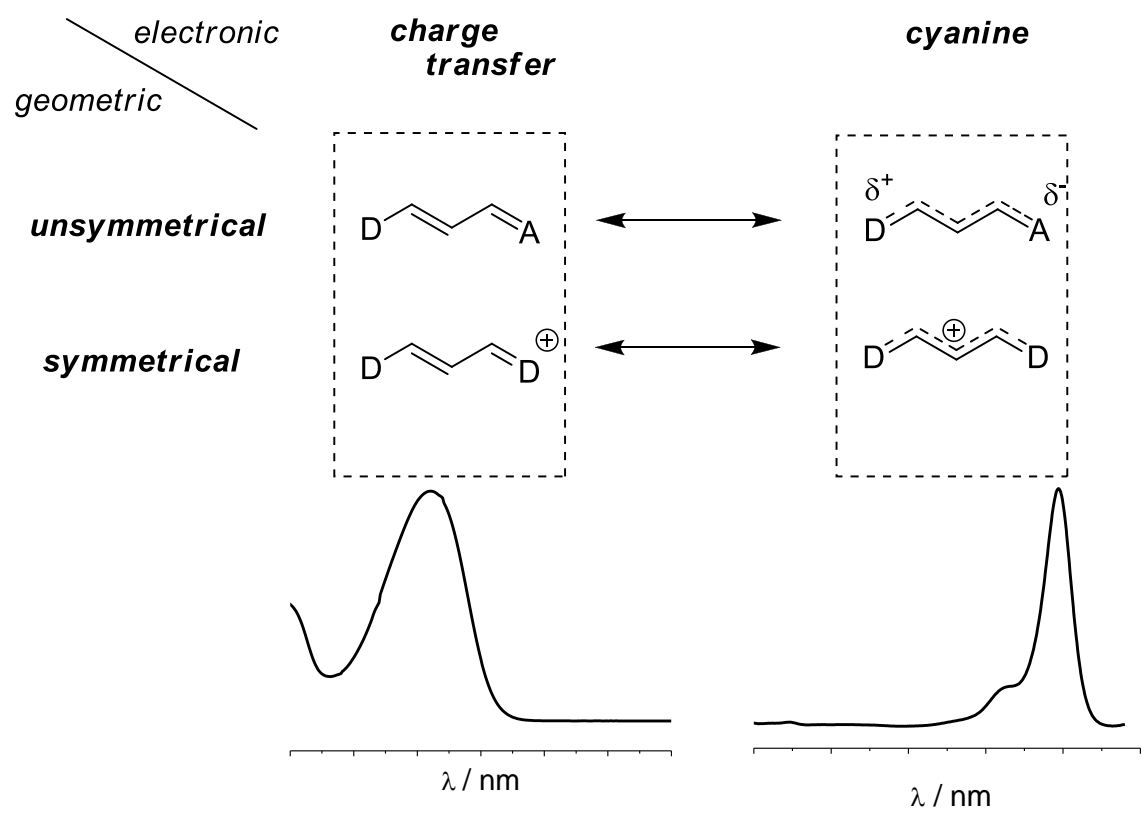

Figure 1. Geometric/electronic paradigm for polymethine dye and corresponding absorption profile.

In our group, we are interested in the second and third order nonlinear optical properties of heptamethine dyes that are chromophores incorporating seven unsaturated carbon atoms and an annelated cyclohexyl ring for the rigidification of the conjugated bridge further decorated by a ter-butyl moieties for solubility and chair configuration immobility reasons. In this context we prepared symmetrical heptamethines DD and AA for optical limiting application $(7,8,15)$ and unsymmetrical heptamethine DA featuring exceptional quadratic hyperpolarisability (16) whose chemical structure and absorption spectra are depicted Figure 2. Symmetrical heptamethines DD and AA display the typical intense and narrow "cyanine-type" absorption which is due to the symmetrical delocalization of the cationic or anionic charge through the $\pi$ backbone. In contrast, unsymmetrical polymethine DA, exhibits a "charge transfer-type" broad absorption. 

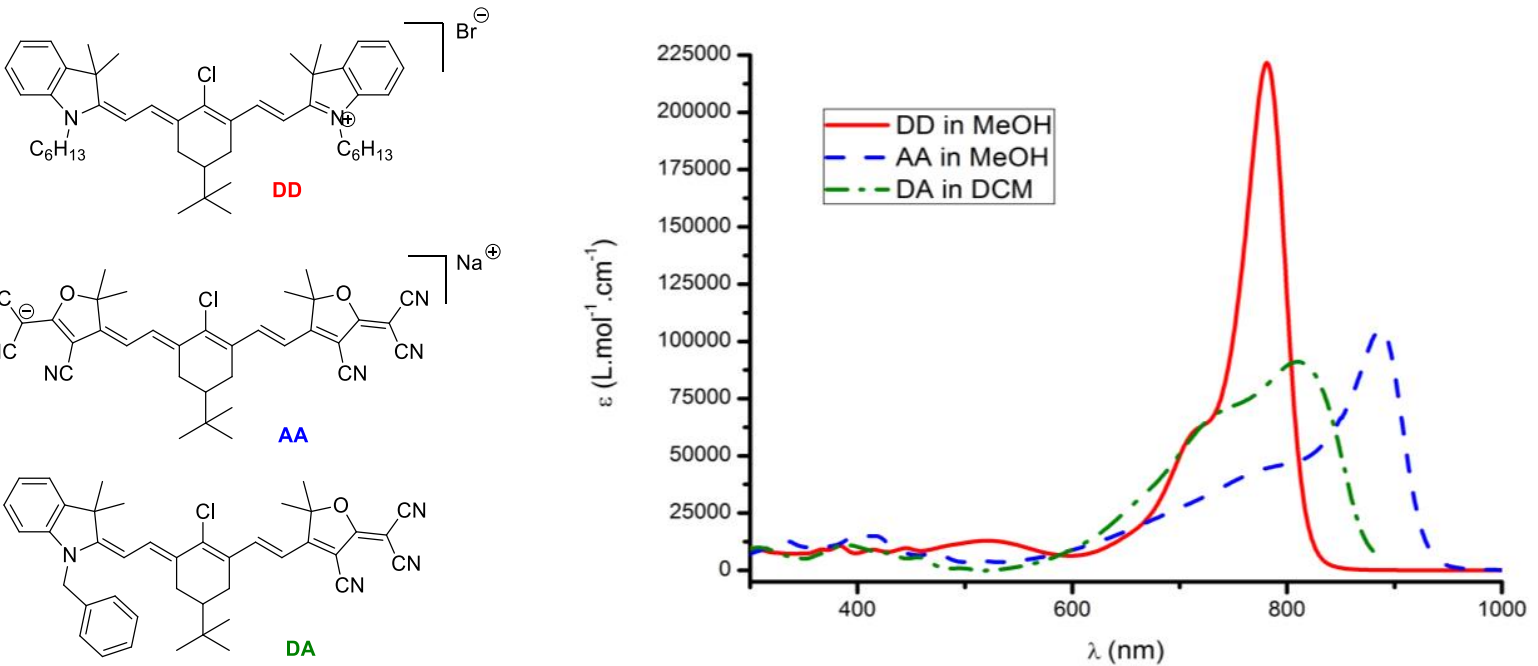

Figure 2. Heptamethines developed by our team and corresponding absorption spectra.

In prevision of incorporation of a polymethine in a solid matrix for further use as optical limiting device, the absorption spectra of a PMMA film doped with chromophore $\mathbf{1}[\mathrm{Br}]$ was recorded (Figure 3 ). A significant broadening of the spectrum is compared to what is observed in solution (Figure 2) and the shape of the solid state spectrum looks closer from that of a CT than that of a pure cyanine. This result was very similar to the thin film absorption spectrum of a bisdioxaborine polymethine salt reported by Marder in 2006. (9) In this exemple, the spin-coated film absorption is also broader than the absorption in a polar solvent.

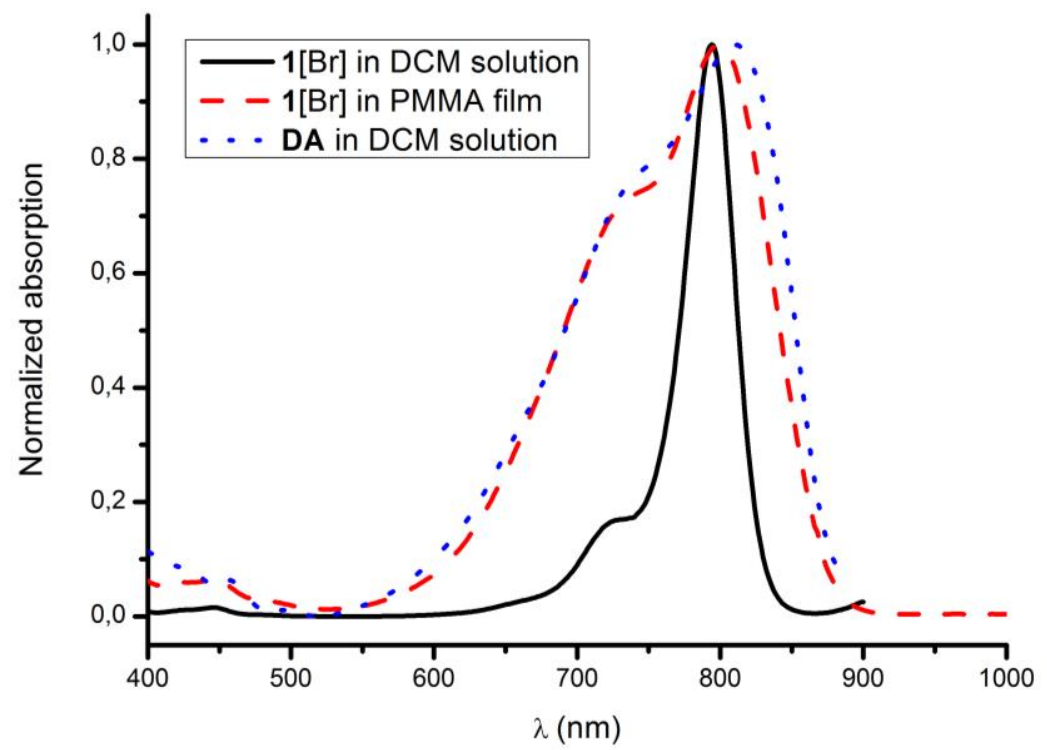

Figure 3. Absorption spectrum of a 1[Br]-doped PMMA film and DCM solution.

Such switch from a cyanine to a dipolar behavior in the case of quite short polymethine is unprecedent and cannot be explained on the basis of the abovementioned Brooker experiment. To explained this cyanine limit crossing, we proposed that the symmetry of the molecule had been broken within the solid matrix, promoting a CT form of the heptamethine (Figure 2). This transition may origin from localization of the cationic charge on one side of the molecule due to a supramolecular ion-pairing effect in the solid state. Indeed the influence of the counter ion on the polymethine absorption behavior has never been investigated previously except in one case where Schuster used chiral counter ion to induced 
circular dichroism in the polymethine cyanine transition. (17) To explore this effect, we decided to study the absorption properties of this molecule $\mathrm{DD}[\mathrm{A}]$ associated with various counter ion of increasing size $\left(\mathrm{A}=\mathrm{Br}, \mathrm{I}_{2} \mathrm{PF}_{6}, \mathrm{SbF}_{6}\right.$, trisphat, borate), in dissociating or non-dissociating solvents or in the solid thin films (Figure 4).

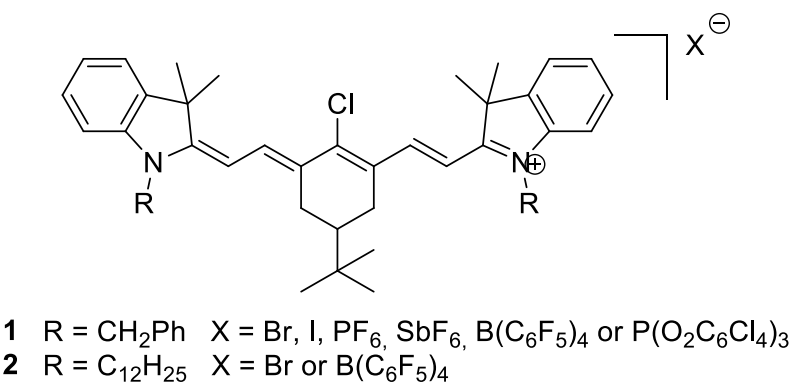

Figure 4. Heptamethine cyanines $\mathbf{1}$ and $\mathbf{2}$ with various counter anions.

\subsection{Ion pairing effect}

In order to fully characterize the impact of ion-pairing on a cyanine, two limit cases were studied in term of optical properties. A heptamethine dye 2, incorporating long aliphatic chains was prepared, enabling good solubility in non-dissociating solvent like toluene. The absorption, emission, quantum yield and lifetime were recorded in dichloromethane and toluene in the cases of a small $[\mathrm{Br}]$ or bulky $\left[\mathrm{B}\left(\mathrm{C}_{6} \mathrm{~F}_{5}\right)_{4}\right]$ counter anions and the results are compiled in the table 1 .
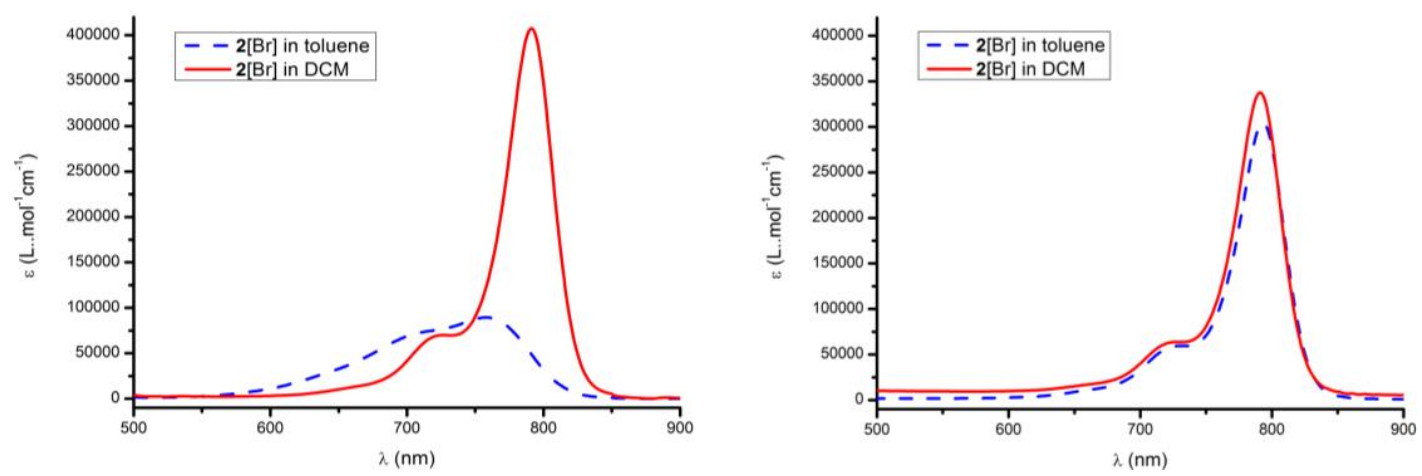

Figure 5. Absorption spectra of $2[\mathrm{Br}]$ (left) and $2\left[\mathrm{~B}\left(\mathrm{C}_{6} \mathrm{~F}_{5}\right)_{4}\right]$ (right) in toluene and dichloromethane.

The absorption spectra of $\mathbf{2}[\mathrm{Br}]$ presented in Figure 5 display a loss of "cyanine-type" absorption in a non-dissociating solvent. This result can be explained by the ion-pairing between the cationic heptamethine and the bromide anion, leading to a charge localization of one side of the polymethine disrupting the symmetry and explaining the formation of a dipolar species in solution. This effect is not observed in dichloromethane where the dye and its counter anion are dissociated. The absorption spectra of $2\left[\mathrm{~B}\left(\mathrm{C}_{6} \mathrm{~F}_{5}\right)_{4}\right]$, featuring a bulky counter anion show that the cyanine character of the absorption is kept whatever the solvent is, proving that the anion is too bulky to approach the cyanine and localize the cationic charge. The optical data presented in table 1 are consistent with this theory and show that the fluorescence quantum yield and lifetime also dramatically decrease when moving from a cyanine to a charge transfer form. 
Table 1. Optical properties of $2[\mathrm{Br}]$ and $2\left[\mathrm{~B}\left(\mathrm{C}_{6} \mathrm{~F}_{5}\right)_{4}\right]$ in toluene and dichloromethane.

${ }^{\mathrm{a}} \mathrm{IR}-125$ as reference $\left(\Phi=13 \%\right.$ in DMSO). ${ }^{\mathrm{b}}$ Excitation at $732 \mathrm{~nm}$.

\begin{tabular}{cccccc}
\hline \multirow{2}{*}{$2[\mathrm{Br}]$} & Solvent & $\lambda_{\max }(\mathrm{nm}) / \varepsilon_{\max }\left(\mathrm{M}^{-1} \cdot \mathrm{cm}^{-1}\right)$ & $\lambda_{\mathrm{em}}(\mathrm{nm})$ & $\Phi(\%)^{\mathrm{a}}$ & $\tau(\mathrm{ns})^{\mathrm{b}}$ \\
& toluene & $758 / 89500$ & 806 & 7 & $>0.4$ \\
\multirow{2}{*}{$2\left[\mathrm{~B}\left(\mathrm{C}_{6} \mathrm{~F}_{5}\right)_{4}\right]$} & DCM & $791 / 408000$ & 808 & 29 & 1.3 \\
& toluene & $793 / 304800$ & 806 & 24 & 1.2 \\
& DCM & $791 / 337800$ & 802 & 29 & 1.3
\end{tabular}

In a second phase, the effect of different sizes of counter anions on the behavior of heptamethine $1(\mathrm{R}=$ benzyl) was studied. A simple anion metathesis permitted to exchange the bromide anion with small $[\mathrm{I}],\left[\mathrm{SbF}_{6}\right],\left[\mathrm{PF}_{6}\right]$ anions or more bulky $\left[\mathrm{B}\left(\mathrm{C}_{6} \mathrm{~F}_{5}\right)_{4}\right]$ and trisphat $\left[\mathrm{P}\left(\mathrm{O}_{2} \mathrm{C}_{6} \mathrm{Cl}_{4}\right)_{3}\right]$ anions. (18) The absorption spectra of these 6 compounds were compared on Figure 6 in a dissociating solvent (dichloromethane, left) and a non-dissociating solvent (toluene, right).
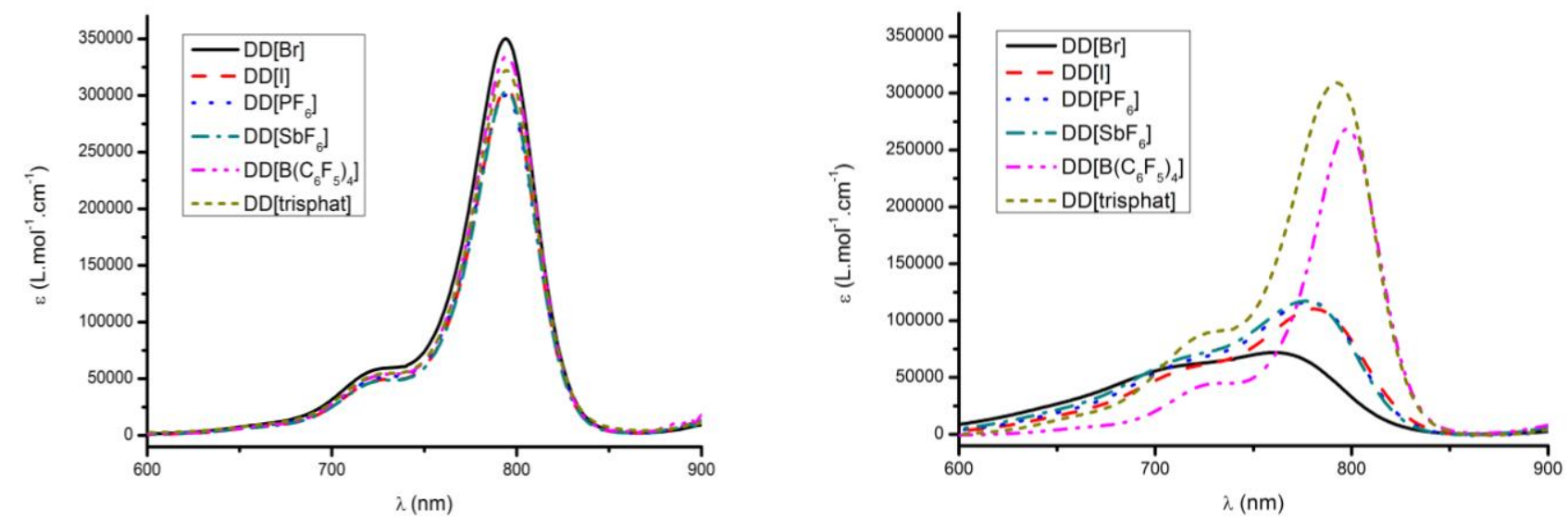

Figure 6. Absorption spectra of $\mathbf{1}[\mathrm{Br}], \mathbf{1}[\mathrm{I}], \mathbf{1}\left[\mathrm{PF}_{6}\right], \mathbf{1}\left[\mathrm{SbF}_{6}\right], \mathbf{1}\left[\mathrm{B}\left(\mathrm{C}_{6} \mathrm{~F}_{5}\right)_{4}\right]$ and $\mathbf{1}$ [trisphat] in dichloromethane (left) and toluene (right).

A first look to the absorption spectra of all these species in dichloromethane (Figure 6, left) shows no influence of the size or nature of the counter anion on the optical properties: typical intense and narrow "cyanine-type" absorption is observed in each case. On the contrary, in a non-dissociating apolar solvent like toluene (Figure 6, right), only the absorption of $\mathbf{1}\left[\mathrm{B}\left(\mathrm{C}_{6} \mathrm{~F}_{5}\right)_{4}\right]$ and $\mathbf{1}$ [trisphat] remain quasi-identical to the absorption in dichloromethane in terms of shape and intensity. In the case of counter anions of decreasing size $\left[\mathrm{SbF}_{6}\right],\left[\mathrm{PF}_{6}\right],[\mathrm{I}]$ and $[\mathrm{Br}]$, the absorption spectra become even broader and less intense, similar to that of dipolar unysmetrical dye DA. According to the main hypothesis we developed, in a non-dissociating solvent, a small counter anion is closely paired to the polymethine, which lead to a localization of the cationic charge on one side of the dye. Because of this charge localization, the cyanine is no more symmetrical and the "cyanine-type" absorption is lost in favor of "charge transfer-type" absorption. In the instance of the two bulkiest counter ions, the hindrance of the anion is too high to permit this interaction and consequeltly no loss of the symmetry is observed. Finally, the absorption of polymethine $\mathbf{1}$ as dopant in PPMA film was recorded for each counter anion and proves that the use of a bulky anion can prevent the ion-pairing in a solid matrix, safeguarding the narrow and intense "cyanine-type" absorption (Figure 7). 


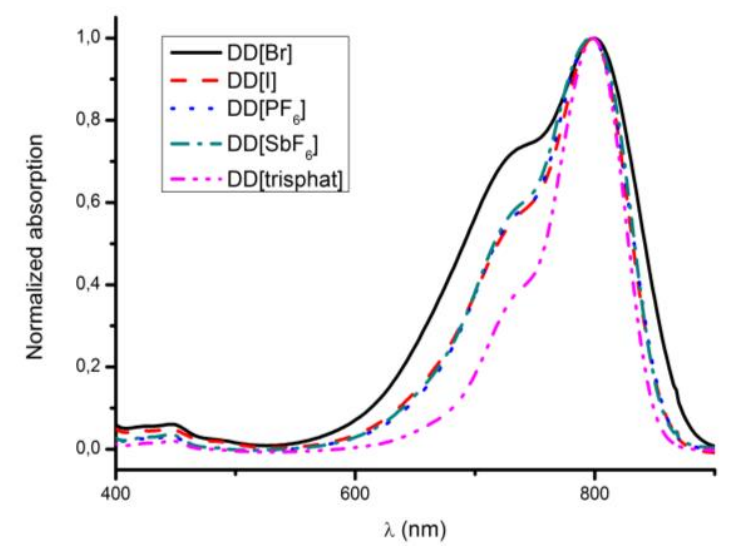

Figure 7. Normalized absorption spectra of $\mathbf{1}[\mathrm{Br}], \mathbf{1}[\mathrm{I}], \mathbf{1}\left[\mathrm{PF}_{6}\right], \mathbf{1}\left[\mathrm{SbF}_{6}\right]$ and 1 [trisphat] as dopant in PMMA films.

\section{Conclusions}

We demonstrated that the nature of the surrounding media (solvent or polymer) can have a dramatic influence on the optical properties of a heptamethine cyanine. The choice of the counter anion revealed to play a leading role in the prevention of ion-pairing effect. This parameter has now to be taken in account for a best control and a right interpretation of the chromophore optical properties in a solid matrix in particular for nonlinear optical or photovoltaic applications. (19)

\section{References}

1. A. Mishra, R. K. Behera, P. K. Behera, B. K. Mishra and G. B. Behera, "Cyanines during the 1990s: A Review," Chem. Rev. 100(6), 1973-2012 (2000)

2. A. V. Kulinich and A. I. Aleksandr, "Merocyanine dyes: synthesis, structure, properties and applications," Russian Chemical Reviews 78(2), 141 (2009)

3. G. Qian and Z. Y. Wang, "Near-Infrared Organic Compounds and Emerging Applications," Chem. Asian J. 5(5), 1006-1029 (2010)

4. L. Yuan, W. Lin, K. Zheng, L. He and W. Huang, "Far-red to near infrared analyte-responsive fluorescent probes based on organic fluorophore platforms for fluorescence imaging," Chemical Society Reviews 42(2), 622-661 (2013)

5. J. M. Hales, J. Matichak, S. Barlow, S. Ohira, K. Yesudas, J.-L. Brédas, J. W. Perry and S. R. Marder, "Design of Polymethine Dyes with Large Third-Order Optical Nonlinearities and Loss Figures of Merit," Science 327(5972), 1485$1488(2010)$

6. J. D. Matichak, J. M. Hales, S. Barlow, J. W. Perry and S. R. Marder, "Dioxaborine- and Indole-Terminated Polymethines: Effects of Bridge Substitution on Absorption Spectra and Third-Order Polarizabilities," J. Phys. Chem. A $115(11), 2160-2168(2011)$

7. $\quad$ P.-A. Bouit, G. Wetzel, G. Berginc, B. Loiseaux, L. Toupet, P. Feneyrou, Y. Bretonnière, K. Kamada, O. Maury and C. Andraud, "Near IR Nonlinear Absorbing Chromophores with Optical Limiting Properties at Telecommunication Wavelengths," Chem. Mater. 19(22), 5325-5335 (2007)

8. Q. Bellier, N. S. Makarov, P.-A. Bouit, S. Rigaut, K. Kamada, P. Feneyrou, G. Berginc, O. Maury, J. W. Perry and C. Andraud, "Excited state absorption: a key phenomenon for the improvement of biphotonic based optical limiting at telecommunication wavelengths," Phys. Chem. Chem. Phys. 14(44), 15299-15307 (2012)

9. J. M. Hales, S. Zheng, S. Barlow, S. R. Marder and J. W. Perry, "Bisdioxaborine Polymethines with Large ThirdOrder Nonlinearities for All-Optical Signal Processing," J. Am. Chem. Soc. 128(35), 11362-11363 (2006) 
10. P.-A. Bouit, R. Westlund, P. Feneyrou, O. Maury, M. Malkoch, E. Malmstrom and C. Andraud, "Dendrondecorated cyanine dyes for optical limiting applications in the range of telecommunication wavelengths," New J. Chem. 33(5), 964-968 (2009)

11. A. Scarpaci, A. Nantalaksakul, J. M. Hales, J. D. Matichak, S. Barlow, M. Rumi, J. W. Perry and S. R. Marder, "Effects of Dendronization on the Linear and Third-Order Nonlinear Optical Properties of Bis(thiopyrylium) Polymethine Dyes in Solution and the Solid State," Chem. Mater. 24(9), 1606-1618 (2012)

12. F. Würthner, G. Archetti, R. Schmidt and H.-G. Kuball, "Solvent Effect on Color, Band Shape, and ChargeDensity Distribution for Merocyanine Dyes Close to the Cyanine Limit," Angew. Chem. Int. Ed. 47(24), 4529-4532 (2008)

13. L. G. S. Brooker, R. H. Sprague, C. P. Smyth and G. L. Lewis, "Color and Constitution. I. Halochromism of Anhydronium Bases Related to the Cyanine Dyes1," J. Am. Chem. Soc. 62(5), 1116-1125 (1940)

14. L. M. Tolbert and X. Zhao, "Beyond the Cyanine Limit: Peierls Distortion and Symmetry Collapse in a Polymethine Dye," J. Am. Chem. Soc. 119(14), 3253-3258 (1997)

15. P.-A. Bouit, E. Di Piazza, S. p. Rigaut, B. Le Guennic, C. Aronica, L. Toupet, C. Andraud and O. Maury, "Stable Near-Infrared Anionic Polymethine Dyes: Structure, Photophysical, and Redox Properties," Org. Lett. 10(19), 4159-4162 (2008)

16. C. Cabanetos, W. Bentoumi, V. Silvestre, E. Blart, Y. Pellegrin, V. Montembault, A. Barsella, K. Dorkenoo, Y. Bretonnière, C. Andraud, L. Mager, L. Fontaine and F. Odobel, "New Cross-Linkable Polymers with Huisgen Reaction Incorporating High $\mu \beta$ Chromophores for Second-Order Nonlinear Optical Applications," Chem. Mater. 24(6), 1143-1157 (2012)

17. P.-A. Bouit, C. Aronica, L. c. Toupet, B. Le Guennic, C. Andraud and O. Maury, "Continuous Symmetry Breaking Induced by Ion Pairing Effect in Heptamethine Cyanine Dyes: Beyond the Cyanine Limit," J. Am. Chem. Soc. 132(12), 4328-4335 (2010)

18. P.-A. Bouit, C. Aronica, L. Guy, A. Martinez, C. Andraud and O. Maury, "Diastereoselective supramolecular ionpairing between the TRISPHAT anion and pro-chiral heptamethine cyanine dyes," Org. Biomol. Chem. 7(15), 3086-3090 (2009)

19. P.-A. Bouit, D. Rauh, S. Neugebauer, J. L. Delgado, E. D. Piazza, S. p. Rigaut, O. Maury, C. Andraud, V. Dyakonov and N. Martin, "A "Cyanine-Cyanine" Salt Exhibiting Photovoltaic Properties," Org. Lett. 11(21), 4806-4809 (2009) 